\title{
Osteomalacia as a cause of chronic pain
}

\author{
Robert W Teasell MD FRCPC, Greg Sue-A-Quan MD, Bernard M Wolfe BM BCh(Oxon) FRCPC
}

\begin{abstract}
RW Teasell, G Sue-A-Quan, BM Wolfe. Osteomalacia as a cause of chronic pain. Pain Res Manage 1996;1(1):69-72.
\end{abstract}

Osteomalacia is a form of metabolic bone disease that can present as chronic pain. A 36-year-old woman presented with a three-year history of bilateral leg and back pain, and proximal leg weakness. Repeated consultations and investigations failed to discover a cause for her pain, and a diagnosis of chronic benign pain was made. She was admitted to hospital where the bone scan, laboratory investigation and bone biopsy established a diagnosis of renal phosphate-wasting adult-onset rickets (osteomalacia). Radiographs of the hip and magnetic resonance imaging revealed bilateral femoral neck fractures and segmental, avascular necrosis of the femoral heads. The patient was treated with high dose phosphate and vitamin D with marked relief of pain. Osteomalacia should be considered in unusual cases of intractable chronic pain.

Key Words: Chronic pain, Hip fractures weakness, Osteomalacia

\section{L’ostéomalacie comme cause de douleur chronique}

RÉSUMÉ : L'ostéomalacie est une forme de maladie métabolique osseuse qui peut se présenter comme une douleur chronique. Une femme de 36 ans s'est présentée avec une douleur dans les deux jambes et dans le dos dont elle souffrait depuis trois ans et, une faiblesse dans la région proximale de la jambe. Plusieurs consultations et investigations n'avaient pas permis de découvrir une cause à sa douleur et un diagnostic de douleur chronique bénigne avait été posé. La patiente a été admise à l'hôpital où une scintigraphie osseuse, des épreuves de laboratoire et une biopsie osseuse ont permis d'établir un diagnostic de rachitisme de l'adulte avec déplétion du phosphate par voie rénale (ostéomalacie). Les radiographies de la hanche et l'imagerie par résonance magnétique nucléaire ont révélé des fractures bilatérales du col du fémur et une nécrose avasculaire en segments des têtes fémorales. La patiente a reçu de fortes doses de phosphate et de vitamine D qui ont entraîné un soulagement important de la douleur. L'ostéomalacie doit être envisagée dans les cas inhabituels de douleur chronique rebelle.
C hronic pain is a common diagnosis and is frequently associated with unexplained weakness. We present an interesting case of adult onset osteomalacia presenting with chronic pain and proximal leg weakness that was diagnosed as 'benign' for several years.

\section{CASE PRESENTATION}

A 36-year-old woman was admitted to a tertiary care hospital rehabilitation unit with an unusual wobbling gait and disabling knee pain of five years' duration. Initially, she complained of pain most prominent over her metatarsal heads and heels, and aggravated by prolonged standing or walking. She was treated with acetylsalicylic acid and orthotics, which partially relieved her foot discomfort. She began walking stiff-legged, which was attributed to her foot pain. A bone scan showing multiple periarticular areas of abnormal increased uptake involving the plantar and dorsal aspect of the right calcaneus and metatarsal phalangeal (MTP) joints bilaterally was interpreted as early degenerative changes with inflammation. Three years before admission to hos- pital she fell and began to experience pain related to the sacroiliac joints, posterior buttocks, left hip and down both legs, followed soon after by proximal leg weakness. She complained of an intermittent lancinating pain down her anterior thighs to her knees. Admission to her local hospital with 'severe low back pain and sciatica' for lumbar traction was not helpful. A computerized tomographic scan of her lumbar spine and a myelogram were normal.

She was subsequently seen by three neurologists, three physiatrists, a rheumatologist and a neurosurgeon for the unexplained backache, bilateral knee pain and leg weakness. The pain was particularly aggravated by rising to a standing posture from either a supine or sitting position. Walking downstairs was particularly troublesome and she had to take one stair at a time. There was no associated sensory defect, or any bladder or bowel complaints. She would occasionally develop leg spasms which extended her knees involuntarily. She had an unusual waddlingtype gait along with slight hyperextension of the knees. Mild decreased range of motion of the hip joints was noted. Three sepa-

Departments of Physical Medicine and Rehabilitation, and Medicine, University of Western Ontario, University Hospital, London, Ontario

Correspondence and reprints: Dr RW Teasell, Department of Physical Medicine and Rehabilitation, University Hospital, 339 Windermere Road, London, Ontario N6A 5A5. Telephone 519-663-3235, fax 519-663-2941

Received for publication August 16, 1995. Accepted December 1, 1995 


\section{TABLE 1}

Laboratory investigations

\begin{tabular}{|c|c|c|}
\hline Test (units) & Value & Normal \\
\hline Serum phosphate on normal diet (mmol/L) & $<0.32$ & $0.80-1.33$ \\
\hline $\begin{array}{l}\text { Serum phosphate during } 3 \mathrm{~g} / \text { day potassium } \\
\text { supplementation }(\mathrm{mmol} / \mathrm{L})\end{array}$ & 0.73 & $0.80-1.33$ \\
\hline Serum calcium (mmol/L) & 2.51 & $2.12-2.62$ \\
\hline Serum 1,25 dihydroxy vitamin $\mathrm{D}(\mathrm{pmol} / \mathrm{L})$ & $<10$ & $25-120$ \\
\hline Serum albumin $(g / L)$ & 41.6 & $30-48$ \\
\hline Serum PTH (midregion) (pmol/L) & 53 & $20-70$ \\
\hline Serum alkaline phosphatase (U/L) & 240 & $16-98$ \\
\hline Serum bicarbonate (mmol/L) & 21 & $24-32$ \\
\hline Serum asparagine $(\mu \mathrm{mol} / \mathrm{L})$ & 171 & $27-111$ \\
\hline Serum cystine $(\mu \mathrm{mol} / \mathrm{L})$ & 4 & $13-113$ \\
\hline Serum glutamic acid ( $\mu \mathrm{mol} / \mathrm{L})$ & 75 & $31-70$ \\
\hline Serum lysine $(\mu \mathrm{mol} / \mathrm{L})$ & 127 & $135-287$ \\
\hline Serum taurine $(\mu \mathrm{mol} / \mathrm{L})$ & 134 & $25-79$ \\
\hline Serum creatine kinase $(\mathrm{U} / \mathrm{L})$ & 22 & $26-140$ \\
\hline Serum IgA and IgM & Normal & Normal \\
\hline $\begin{array}{l}\text { Urinary phosphate excretion on normal diet } \\
\qquad(\mathrm{mmol} / \text { day })\end{array}$ & 18.6 & $11-32$ \\
\hline $\begin{array}{l}\text { Urinary phosphate excretion during } 3 \mathrm{~g} / \text { day } \\
\text { phosphate supplementation (mmol/day) }\end{array}$ & 63.8 & $11-32$ \\
\hline Urinary calcium excretion (mmol/day) & 4.1 & $1.3-10$ \\
\hline Urinary protein excretion (mg/day) & 275 & (normal) \\
\hline Urinary metabolic screen & \multicolumn{2}{|c|}{ Trace of glycinuria } \\
\hline Urinary glucose (mmol/L) & \multicolumn{2}{|c|}{ Varied from 0 to 14} \\
\hline $\begin{array}{l}\text { Fecal fat excretion on normal diet } \\
(\mathrm{mmol} / \text { day })\end{array}$ & 6 & 5.3-13.9 \\
\hline
\end{tabular}

rate electromyelogram studies, conducted because of the proximal muscle weakness, revealed no abnormalities. Whether she had an inflammatory myopathy despite a creatine phosphokinase level of less then $25 \mathrm{U}$ (normal 26 to $140 \mathrm{U}$ ) was questioned. Initial x-rays demonstrated a suggestion of periarticular osteoporosis involving the proximal interphalangeal and MTP joints of both feet. She was eventually labelled as having a variant of chronic pain syndrome and it was recommended she undergo a progressive exercise program. She was ill-advised that her pain was benign and she should learn to accept it.

This patient was finally referred to a tertiary care hospital for an aggressive rehabilitation program to treat supposed 'nonorganic' weakness with associated unusual gait pattern and chronic pain. At this time she complained primarily of pain around the patellae although pain was also present in her back, feet and upper extremities. Physical examination showed that she walked very laboriously using two canes. She had a stiff-legged gait along with tremulousness of her legs. There were no knee findings. There was a give-way, ratchet-type of weakness in the lower extremities. Sensation was intact, and reflexes were $2+$ and equal bilaterally. Paradoxically, she performed her exercises well

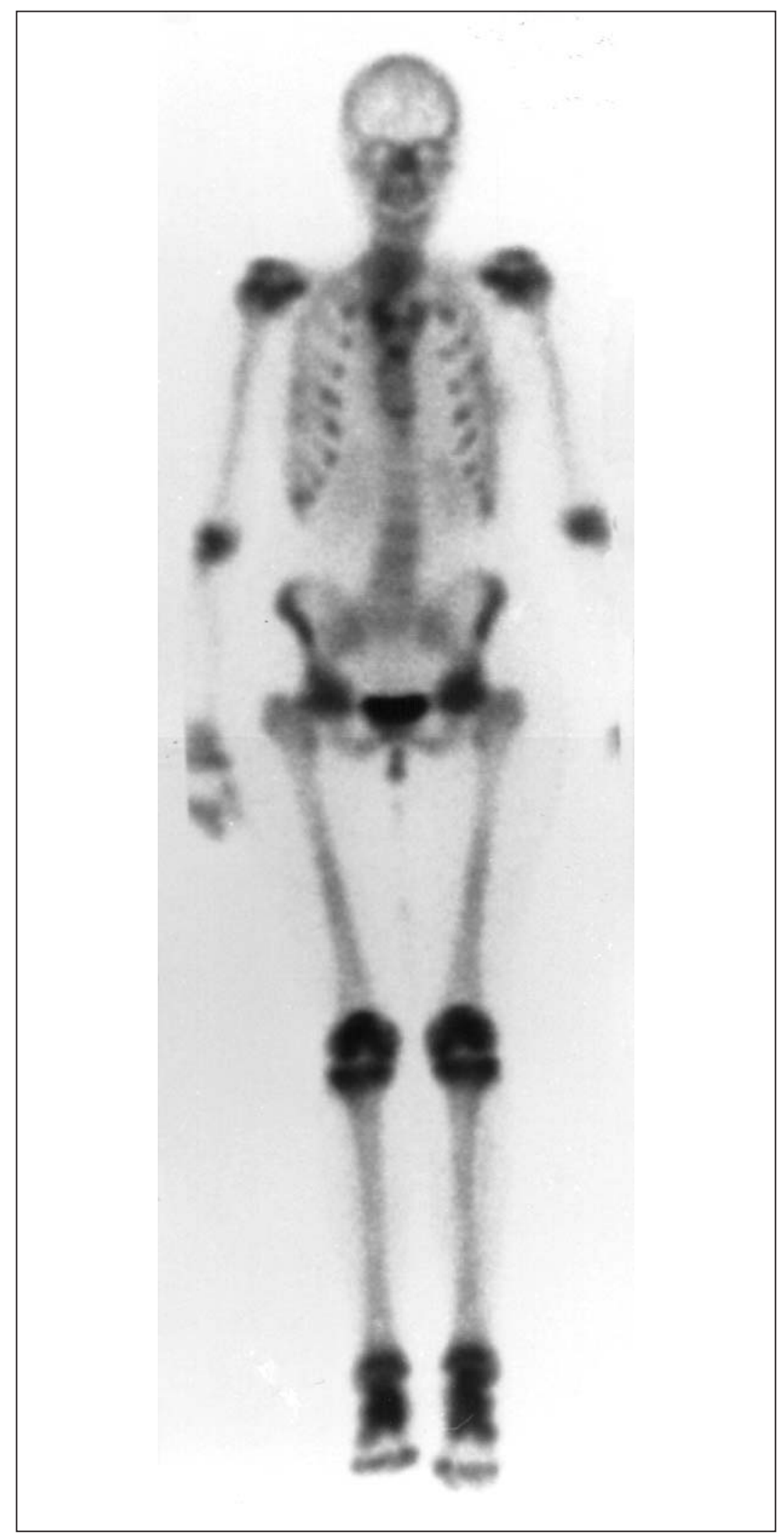

Figure 1) Nuclear bone scan demonstrating diffuse increased bone activity that is predominantly periarticular

while lying down, but did poorly while standing or weightbearing, with significant grimacing and signs of pain behaviour at which point she appeared to be severely disabled. This cast suspicion on the veracity of her physical complaints.

Laboratory investigation at the time of her last admission revealed low serum phosphate and 1,25 dihydroxy vitamin D levels with normal serum calcium and parathyroid hormone levels (Table 1). Bone mineral densities ranged from 39 to $67 \%$ of those of normal age- and sex-matched subjects (actual values: femoral trochanter $0.28 \mathrm{~g} / \mathrm{cm}^{2}$, Ward's angle $0.40 \mathrm{~g} / \mathrm{cm}^{2}$, femoral neck $0.50 \mathrm{~g} / \mathrm{cm}^{2}$, intertrochanteric region $0.70 \mathrm{~g} / \mathrm{cm}^{2}$, lumbar spine $0.72 \mathrm{~g} / \mathrm{cm}^{2}$ ). Bone scan showed diffuse increased bone activity 


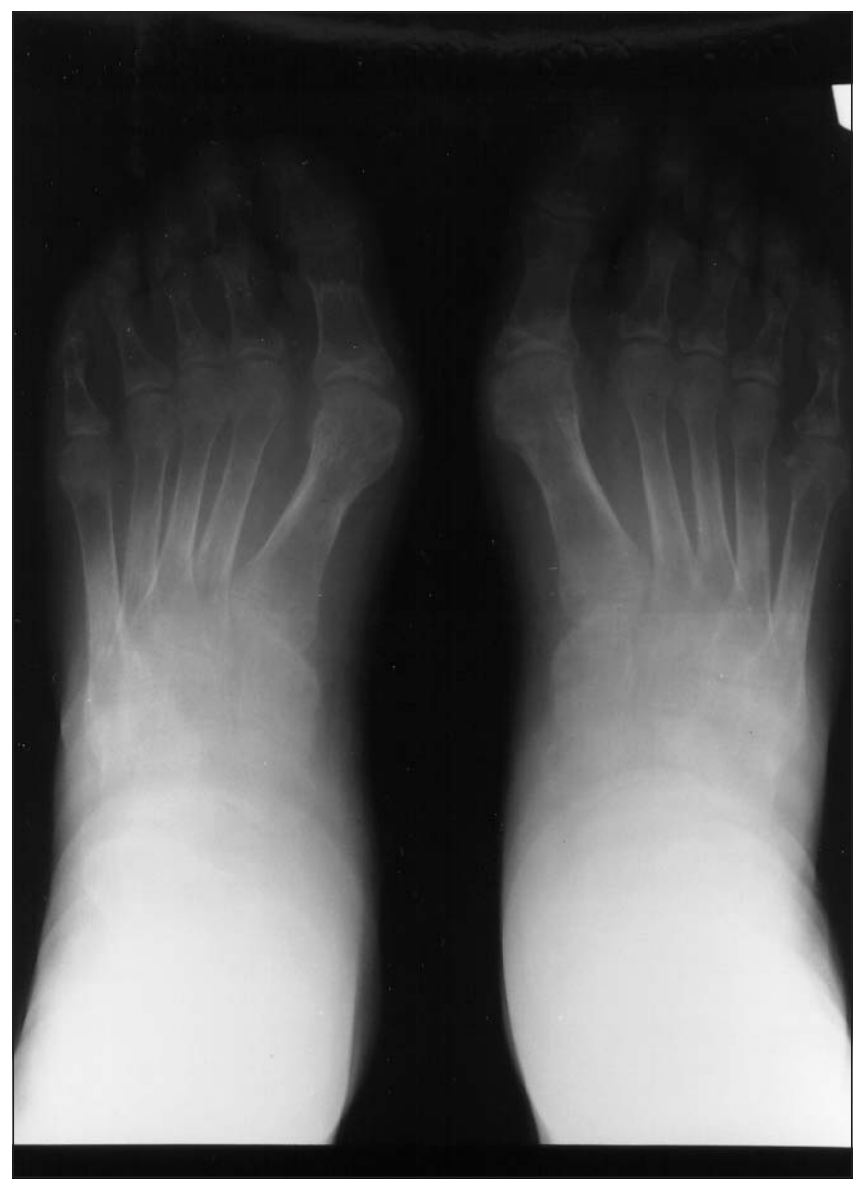

Figure 2) Radiograph of patient's feet demonstrating severe osteopenia

involving predominantly all joints (Figure 1). Biopsy of bone embedded in paraffin and plastic showed a marked mineralization defect with predominance of osteoid and scant evidence of mineralization. Skeletal survey showed severe osteopenia (Figure 2). Apparent fractures at the base of both first metacarpals consistent with 'Looser's transformer zones' were also noted (Figure 3).

Most interesting were x-rays of her hips, which showed fractures of both femoral necks with some cephalad migration of the neck relative to the head of the femur (Figure 4). There were also large bilateral segmental subchondromatous signal abnormalities on magnetic resonance imaging consistent with segmental avascular necrosis in both femoral heads (Figure 5). After consultation whether she would require urgent stabilization of hip fractures by pinning, the decision was made to treat her medically. Treatment was initiated with $1 \mathrm{~g}$ elemental phosphorous twice daily (supplied as sodium acid phosphate) and $1 \mathrm{~g}$ alphacalcidol, with a subsequent increase in the phosphate dose to $3.5 \mathrm{~g} /$ day and alphacalcidol to $2 \mathrm{~g}$ daily over two months. Six weeks after discharge her x-rays showed signs of recalcification. She had noted significant improvements in both strength and pain control. Four months following discharge she was virtually pain-free but still suffered from significant proximal leg weakness and still required two canes to ambulate.

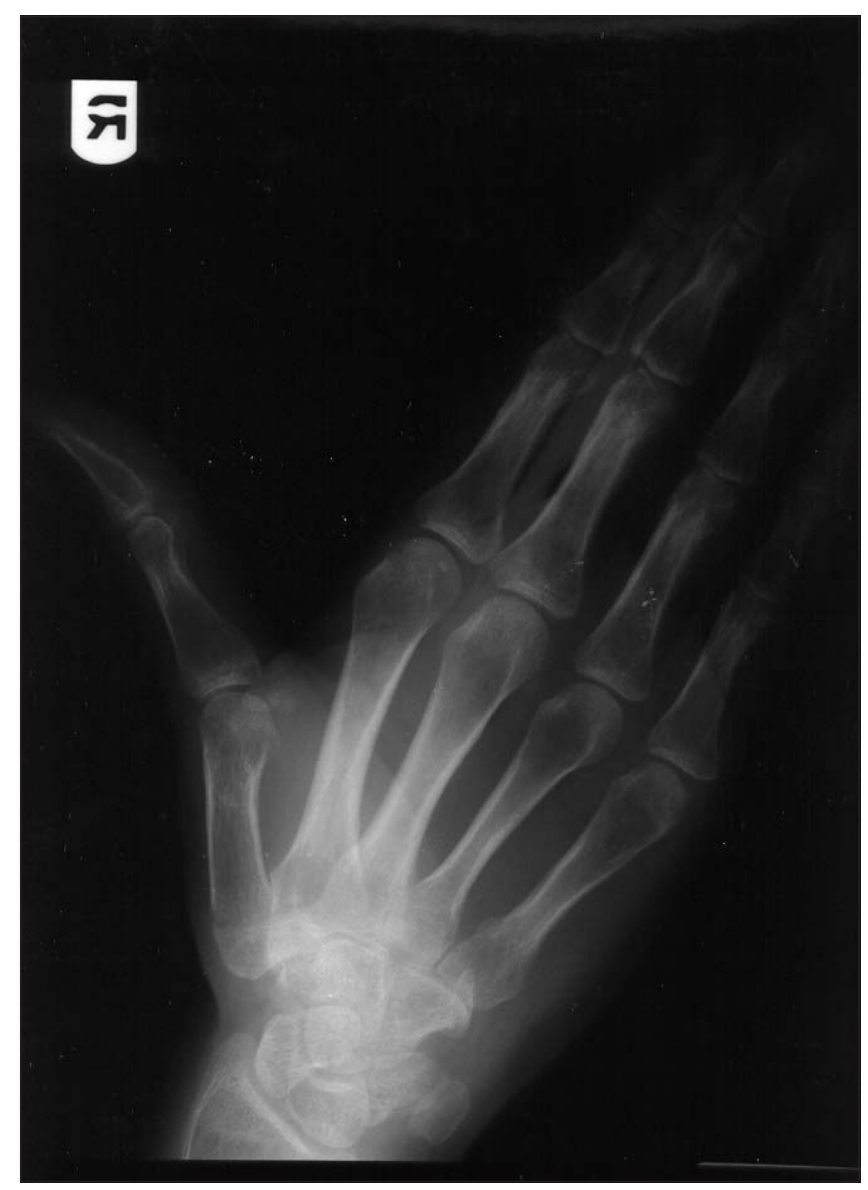

Figure 3) Radiograph showing 'Looser's zone' apparent at the base of the first metacarpal bone

\section{DISCUSSION}

This patient's clinical presentation and laboratory investigations were consistent with sporadic hypophosphatemic rickets or osteomalacia. Secondary causes and associated conditions that must be excluded in making a diagnosis include mesenchymal tumours, chronic ingestion of phosphate binders, Fanconi's syndrome, renal tubular acidosis and hypercalciuric hypophosphatemia. Absence of either short stature, a childhood history of rickets, osteosclerosis or a family history of rickets rendered a diagnosis of hereditary (x-linked) hypophosphatemia unlikely.

The majority of patients with sporadic, adult-onset hypophosphatemia have bone pain, muscle weakness, gait disturbances and characteristic x-ray changes (1). The pain is dull and poorly localized, and is felt more in the bones than the joints. Pain is made worse with weight-bearing and is most commonly felt in the axial skeleton. Percussion tenderness over the shins may be present but pain felt below the knee is uncommon. Lequesve (2) reported on a presentation by Mazili regarding a pseudofibromyalgia syndrome consisting of diffuse muscular pain, asthenia and depressive tendency in three patients aged 30 to 42 years attributed to hypophosphatemia caused by a renal wasting phosphorous disorder. Lequesve (2) also reported on a study by Amor of eight patients with symptoms of polymyalgia, asthenia and de- 


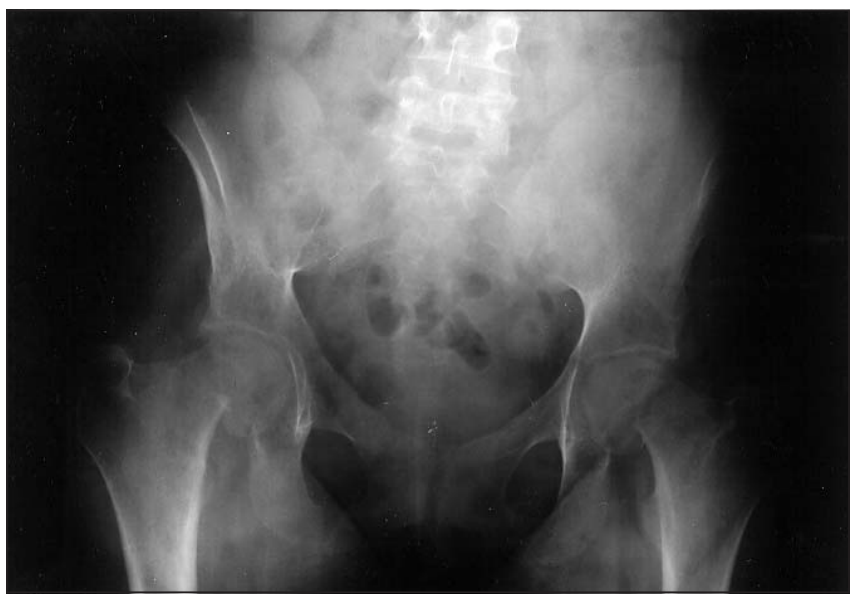

Figure 4) Anteroposterior pelvic radiograph demonstrating fractures of both femoral necks with cephalad migration of the femoral neck relative to the head of the femur

rate electromyelogram studies, conducted because of the proximal muscle weakness, revealed no abnormalities. Whether she had an inflammatory myopathy despite a creatine phosphokinase level of less then $25 \mathrm{U}$ (normal 26 to $140 \mathrm{U}$ ) was questioned. Initial x-rays demonstrated a suggestion of periarticular osteoporosis involving the proximal interphalangeal and MTP joints of both feet. She was eventually labelled as having a variant of chronic pain syndrome and it was recommended she undergo a progressive exercise program. She was ill-advised that her pain was benign and she should learn to accept it.

This patient was finally referred to a tertiary care hospital for an aggressive rehabilitation program to treat supposed 'nonorganic' weakness with associated unusual gait pattern and chronic pain. At this time she complained primarily of pain around the patellae although pain was also present in her back, feet and upper extremities. Physical examination showed that she walked very laboriously using two canes. She had a stiff-legged gait along with tremulousness of her legs. There were no knee findings. There was a give-way, ratchet-type of weakness in the lower extremities. Sensation was intact, and reflexes were $2+$ and equal bilaterally. Paradoxically, she performed her exercises well while lying down, but did poorly while standing or weightbearing, with significant grimacing and signs of pain behaviour at which point she appeared to be severely disabled. This cast suspicion on the veracity of her physical complaints.

and alphacalcidol to $2 \mathrm{~g}$ daily over two months. Six weeks after discharge her x-rays showed signs of recalcification. She had noted significant improvements in both strength and pain control. Four months following discharge she was virtually pain-free but still suffered from significant proximal leg weakness and still required two canes to ambulate.

\section{DISCUSSION}

This patient's clinical presentation and laboratory investigations were consistent with sporadic hypophosphatemic rickets or osteomalacia. Secondary causes and associated conditions that

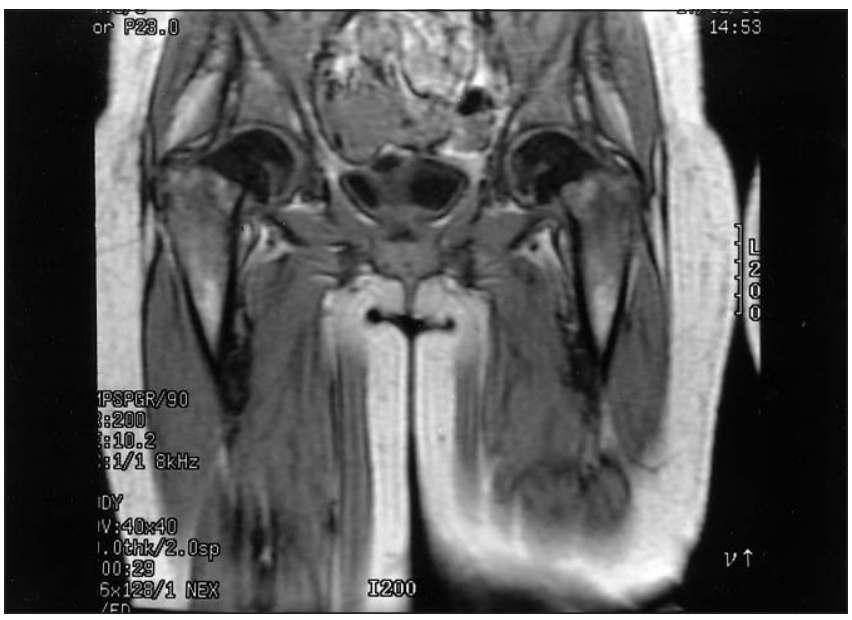

Figure 5) Magnetic resonance image of the hips demonstrating large bilateral segmental subchondromatous signal abnormalities consistent with segmental avascular necrosis in both femoral heads

Laboratory investigation at the time of her last admission revealed low serum phosphate and 1,25 dihydroxy vitamin D levels with normal serum calcium and parathyroid hormone levels (Table 1). Bone mineral densities ranged from 39 to $67 \%$ of those of normal age- and sex-matched subjects (actual values: femoral trochanter $0.28 \mathrm{~g} / \mathrm{cm}^{2}$, Ward's angle $0.40 \mathrm{~g} / \mathrm{cm}^{2}$, femoral neck $0.50 \mathrm{~g} / \mathrm{cm}^{2}$, intertrochanteric region $0.70 \mathrm{~g} / \mathrm{cm}^{2}$, lumbar spine $0.72 \mathrm{~g} / \mathrm{cm}^{2}$ ). Bone scan showed diffuse increased bone activity involving predominantly all joints (Figure 1). Biopsy of bone embedded in paraffin and plastic showed a marked mineralization defect with predominance of osteoid and scant evidence of mineralization. Skeletal survey showed severe osteopenia (Figure 2). Apparent fractures at the base of both first metacarpals consistent with 'Looser's transformer zones' were also noted (Figure 3).

Most interesting were x-rays of her hips, which showed fractures of both femoral necks with some cephalad migration of the neck relative to the head of the femur (Figure 4). There were also large bilateral segmental subchondromatous signal abnormalities on magnetic resonance imaging consistent with segmental avascular necrosis in both femoral heads (Figure 5). After consultation whether she would require urgent stabilization of hip fractures by pinning, the decision was made to treat her medically. Treatment was initiated with $1 \mathrm{~g}$ elemental phosphorous twice daily (supplied as sodium acid phosphate) and $1 \mathrm{~g}$ alphacalcidol, with a subsequent increase in the phosphate dose to $3.5 \mathrm{~g} /$ day

must be excluded in making a diagnosis include mesenchymal tumours, chronic ingestion of phosphate binders, Fanconi's syndrome, renal tubular acidosis and hypercalciuric hypophosphatemia. Absence of either short stature, a childhood history of rickets, osteosclerosis or a family history of rickets rendered a diagnosis of hereditary (x-linked) hypophosphatemia unlikely.

The majority of patients with sporadic, adult-onset hypophosphatemia have bone pain, muscle weakness, gait disturbances and characteristic x-ray changes (1). The pain is dull and poorly localized, and is felt more in the bones than the joints. Pain is 
made worse with weight-bearing and is most commonly felt in the axial skeleton. Percussion tenderness over the shins may be present but pain felt below the knee is uncommon. Lequesve (2) reported on a presentation by Mazili regarding a pseudofibromyalgia syndrome consisting of diffuse muscular pain, asthenia and depressive tendency in three patients aged 30 to 42 years attributed to hypophosphatemia caused by a renal wasting phosphorous disorder. Lequesve (2) also reported on a study by Amor of eight patients with symptoms of polymyalgia, asthenia and depression, all of whom had decreased phosphorous reabsorption by the kidneys with hypophosphatemia.

Proximal muscle weakness affecting predominantly the lower limb girdle ranges from mild to disabling. Muscle atrophy tends to be mild compared with the degree of weakness, and tone is reduced; fasciculations are absent and deep tendon reflexes are increased (3). Gait disturbances are due to pain, weakness or both. In advanced cases, a classic penguin- or duck-like waddling gait may develop. The onset can be at any age, but the majority of patients present between age 20 and 50 years. Frequently the diagnosis is delayed for years, which leads to crippling deformities of the long bones, sclerosis and kyphosis. Generalized osteopenia, pronounced cortical thinning and multiple fractures, especially of the femoral neck, are common. Multiple compression fractures, loss of truncal height and kyphosis occur approximately one to two years after symptoms due to vertebral osteopenia $(1,4)$. Biochemically, serum calcium tends to be normal, alkaline phosphatase levels are normal or elevated and a low 1,25 dihydroxy vitamin D hormone level is typical. Urinary excretion of glycine is often elevated. Fanconi's syndrome with aminoaciduria and glycosuria may be present.

The pathogenesis of the present disorder is unknown, but impaired reabsorption of phosphate by the kidneys has been generally accepted to play a role. Some secondary cases have been cured by removal of mesenchymal tumours (5). Such tumours may secrete a humoral agent that impairs renal phosphate reabsorption (6), inhibits 1-alpha hydroxylation and/or promotes increased osteoclast-mediated bone resorption (1). Treatment involves vitamin $\mathrm{D}$ and phosphate supplementation to increase serum phosphate levels, which reverses the osteomalacia and subsequently relieves symptoms. The main potentially serious side effect of treatment is hypercalcemic hyperparathyroidism $(7,8)$. Lequesve $(2)$ reported that Mazili noted three patients with diffuse myalgia secondary to hypophosphatemia improved clinically with calcium and calcitriol. Lequesve (2) also reported on Amor's presentation of eight patients with polymyalgia and asthenia, of whom six did well with large doses of calcitriol and phosphorous adjusted according to the calcium and phosphorus levels. Improvement of symptoms was delayed several months following normalization of phosphatemia.

\section{CONCLUSIONS}

The complex pattern of skeletal and metabolic findings in the case presented was consistent with a rare diagnosis of sporadic vitamin D-resistant rickets, associated with impaired tubular resorption of phosphate, and 1,25 dihydroxy vitamin D deficiency. As expected, the clinical response to therapy was gratifying with rapid progressive reduction of pain and improvement in mobility.
In unusual cases of intractable or chronic pain, osteomalacia as a diagnosis should be considered. Lequesve (2) has proposed that hypophosphatemia should be excluded before diagnosing fibromyalgia of unknown origin.

ACKNOWLEDGEMENTS: The elemental phosphorous supplied as sodium acid phosphate was donated by Sandoz Canada, and the alphacalcidol was supplied by Leo Laboratories Canada.

\section{REFERENCES}

1. Parfitt AM. Osteomalacia and related disorders. In: Avioli LV, Krane SM, eds. Metabolic Bone Disease, 2nd edn. New York: Grune and Stratton, 1990:329-96.

2. Lequesve M. Hypophosphatemia presents as pseudo fibromyalgia. Presented at the 7th French Congress of Rheumatology, Paris, France, November 23-25, 1994. Rheumatology 1995;9:6.

3. Schott GD, Wills MR. Muscle weakness in osteomalacia. Lancet 1976;i:626-9.

4. Dent CE, Stamp TCB. Hypophosphatemic osteomalacia presenting in adults. Q J Med 1971;40:303-29.

5. Ryan EA, Reiss E. Oncogenous osteomalacia. Review of the world literature of 42 cases and report of 2 new cases. Am J Med 1984;77:501-12.

6. Cai Q, Hodgson SF, Kao PC, et al. Inhibition of renal phosphate transport by a tumor product in a patient with oncogenic osteomalacia. N Engl J Med 1994;330:1645-9.

7. Firth RG, Grant CS, Riggs BL. Development of hypercalcemic hyperparathyroidism after long-term phosphate supplementation in hypophosphatemic osteomalacia. Report of two cases. Am J Med 1985;78:669-73.

8. Reid IR, Teitelbaum SL, Dusson A, Whyte MP. Hypercalcemic hyperparathyroidism complicating oncogenic osteomalacia. Am J Med 1987;83:350-4. 


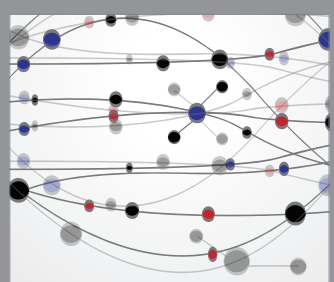

The Scientific World Journal
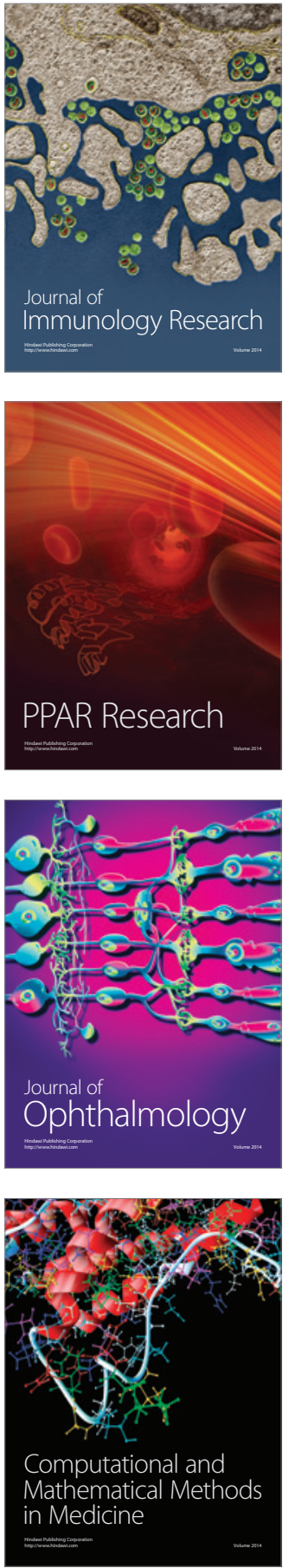

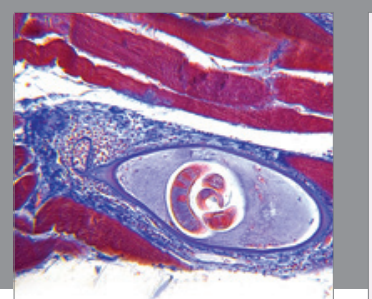

Gastroenterology Research and Practice

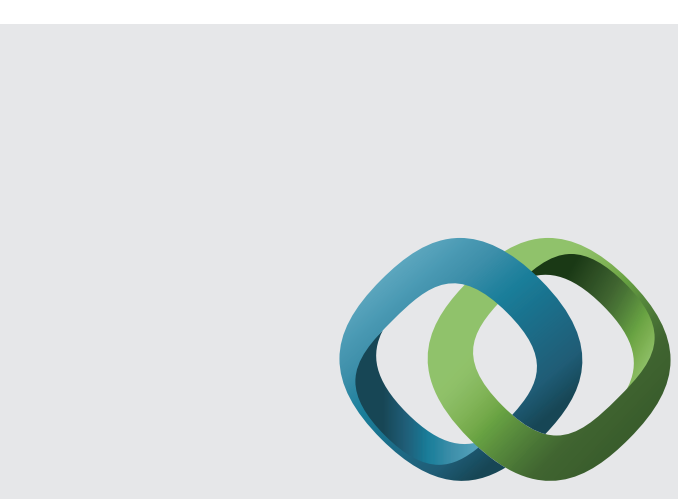

\section{Hindawi}

Submit your manuscripts at

http://www.hindawi.com
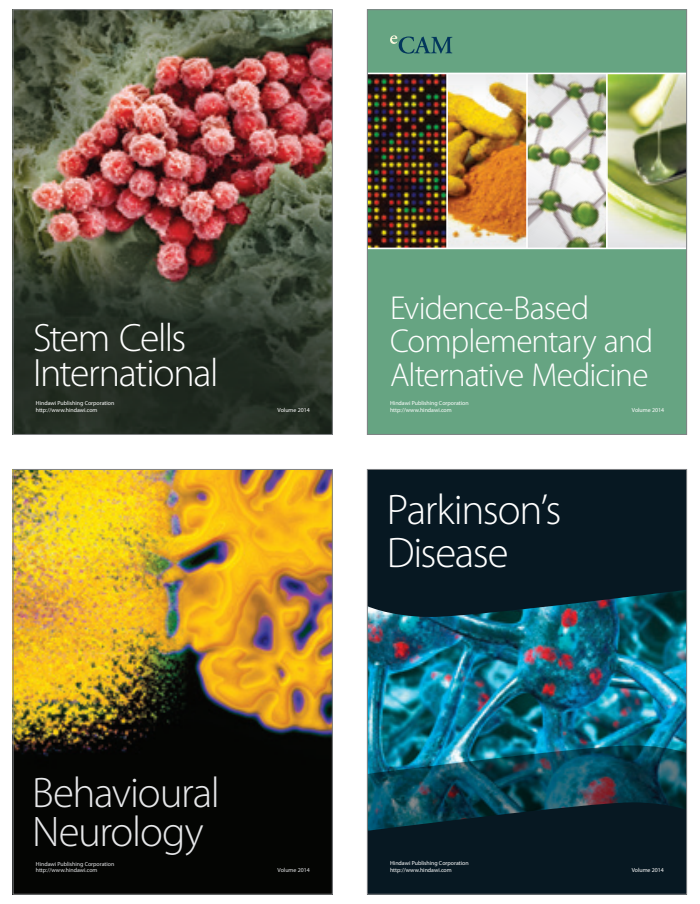
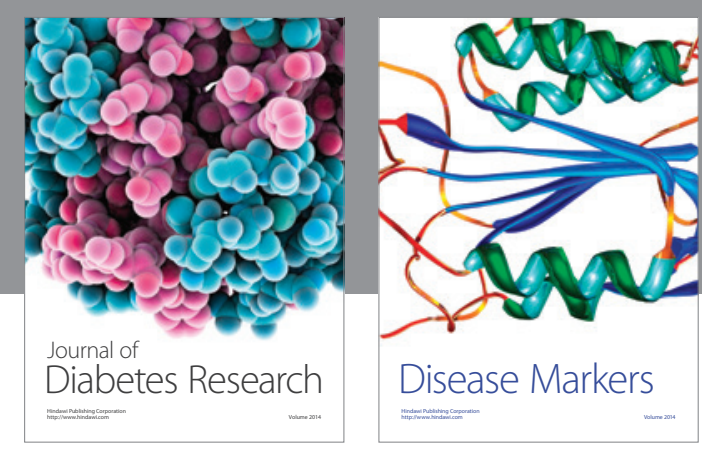

Disease Markers
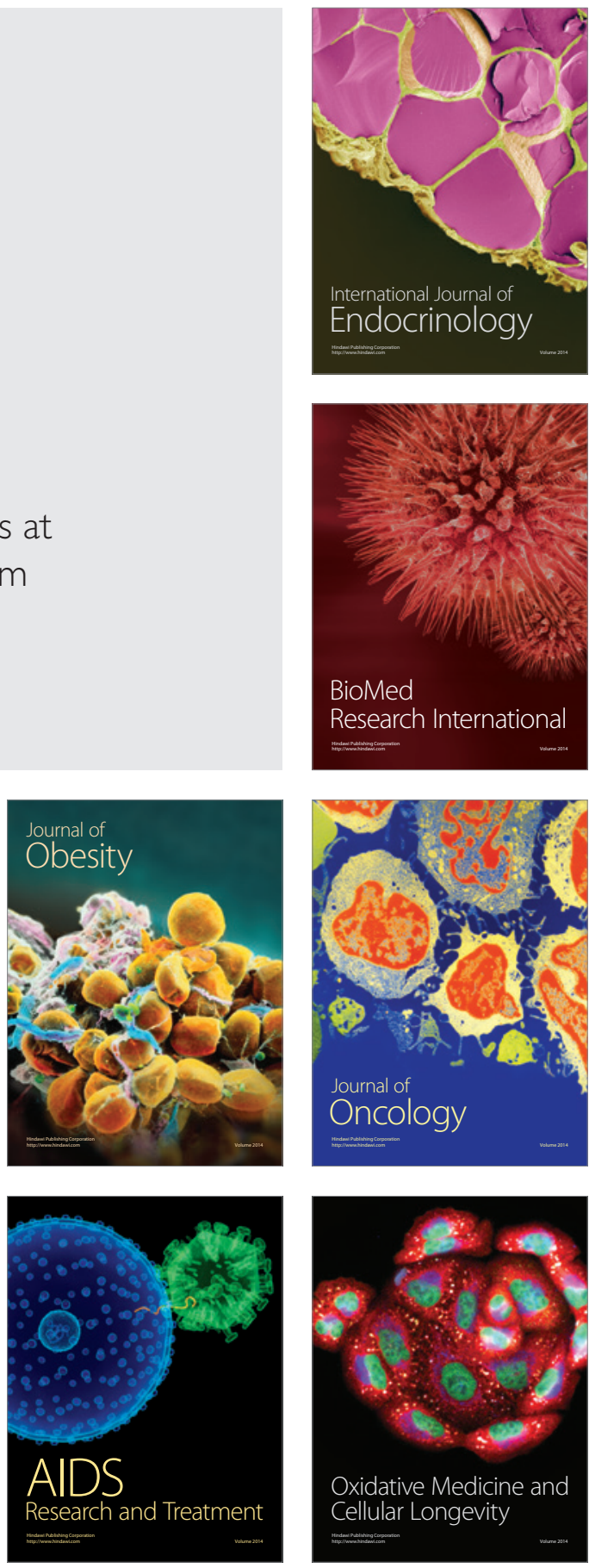